This item was submitted to Loughborough's Research Repository by the author.

Items in Figshare are protected by copyright, with all rights reserved, unless otherwise indicated.

\title{
CO2 laser processing of multi-layer packaging films
}

PLEASE CITE THE PUBLISHED VERSION

PUBLISHER

(C) IMechE / Professional Engineering Publishing

LICENCE

CC BY-NC-ND 4.0

REPOSITORY RECORD

Brown, Neil, Fangmin Shi, David Kerr, Michael R. Jackson, and Robert M. Parkin. 2019. "CO2 Laser Processing of Multi-layer Packaging Films". figshare. https://hdl.handle.net/2134/2131. 
This item was submitted to Loughborough's Institutional Repository (https://dspace.lboro.ac.uk/) by the author and is made available under the following Creative Commons Licence conditions.

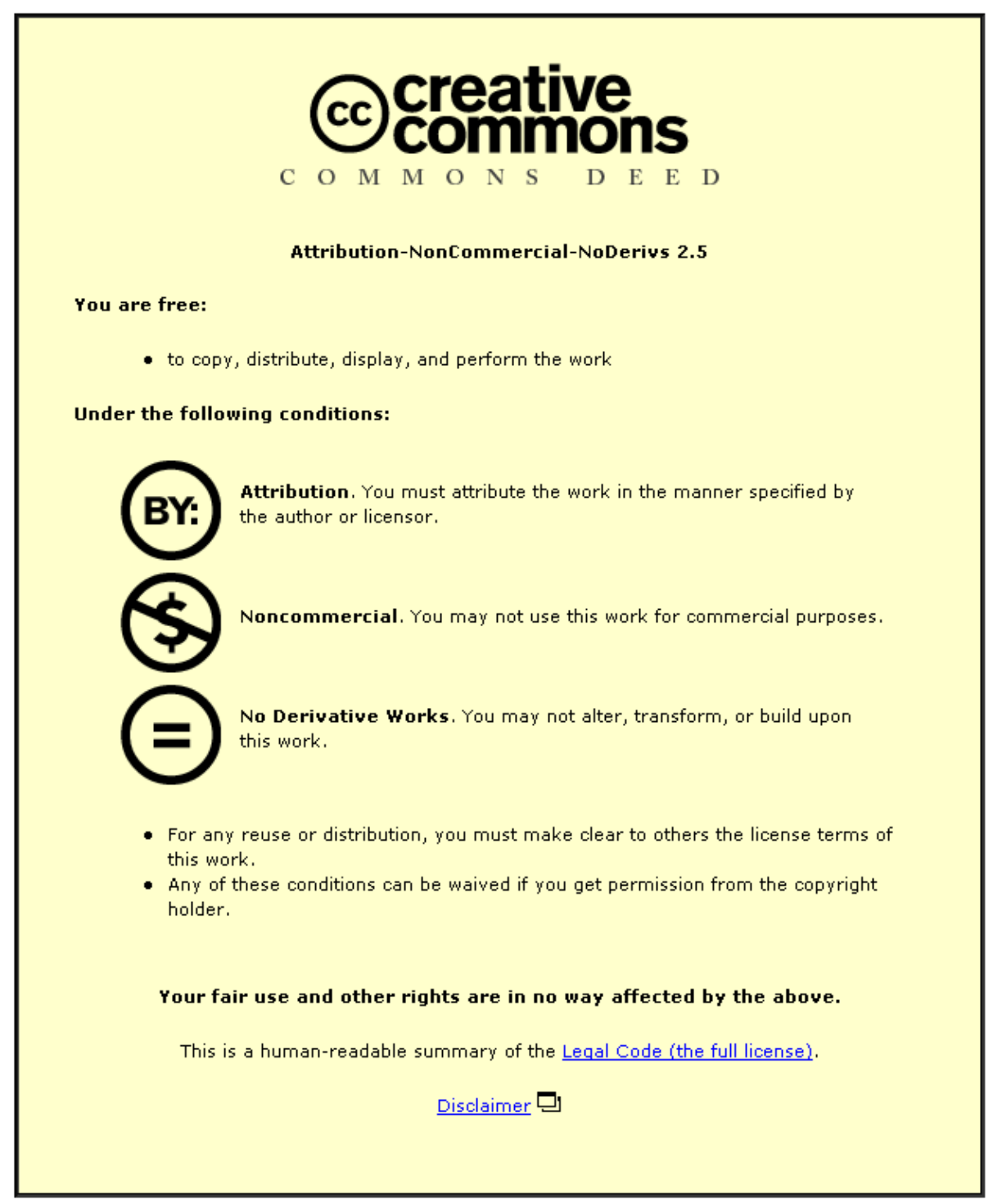

For the full text of this licence, please go to: http://creativecommons.org/licenses/by-nc-nd/2.5/ 


\title{
$\mathrm{CO}_{2}$ laser processing of multilayer packaging films
}

N Brown*, F Shi, D Kerr, M R Jackson, and R M Parkin

Mechatronics Research Group, Wolfson School of Mechanical and Manufacturing Engineering, University of

Loughborough, Loughborough, UK

The manuscript was received on 19 January 2004 and was accepted after revision for publication on 24 January 2005.

DOI: $10.1243 / 095965105 X 9560$

\begin{abstract}
This paper describes a mechatronic approach to the design and implementation of a noncontact sealing system for multilayer lidding films, as used in aseptic containers for food and medical packaging. The method proposed uses a beam-steered laser to seal the product, thereby enabling virtually instant changeover from one product line to another while reducing sealing machine tooling costs and downtime. Results are presented which show that the process may produce seals of higher strength than the conventional thermal/mechanical process.
\end{abstract}

Keywords: laser, sealing, welding, polymer, packaging, aseptic, food, medical

\section{INTRODUCTION}

The internal parts of a conventional heat sealing machine are shown in Fig. 1. The intention is to remove the need for the heated sealing head and replace it with a scanning laser system.

Conventional packaging sealing machinery relies upon a heated plate, contained within the sealing head, pressed onto the lidding film to provide a heat seal. Inside the sealing head also are thermocouples for temperature control, and blades for trimming the film around food pots. These parts, and heater coils, require periodic replacement. A typical heat sealing head may cost $£ 6000$, and a different one is required for each pot shape. A typical food producer may require capacity for upwards of ten pot shapes. A scanning laser system, however, may cost as little as $£ 20000$ and would be capable of processing an unlimited number of pot designs, both for sealing and cutting away of excess film. Set-up times between production runs would be virtually eliminated. Premium cook/chill or ovenable meals are typically low-volume, fast-demand products which would benefit from the reduced production costs inherent in a tool-free sealing system.

\footnotetext{
* Corresponding author: Mechatronics Research Group, Wolfson School of Mechanical and Manufacturing Engineering, Faculty of Engineering, University of Loughborough, Loughborough LE11 3TU, UK. email: n.brown@lboro.ac.uk
}

\subsection{Background}

In order to build a contactless sealing system, a pilot study was undertaken to assess the feasibility of the laser welding process [1]. Other work has since been carried out [2] in the welding of white and transparent thin polypropylene and polyethylene films of low and high density, at speeds of $20 \mathrm{~m} / \mathrm{s}$ using a $\mathrm{CO}_{2}$ laser. A weld strength of the order of 50-60 per cent of material strength was achievable at scan speeds of $10 \mathrm{~m} / \mathrm{s}$. Work carried out at INETI, Portugal [3], noted decreased laser absorption for films of the order of $100 \mu \mathrm{m}$ thickness over thicker samples. For thinner films, therefore, a reflective medium beneath the samples was used to produce total absorption. A $3 \mathrm{~kW}$ laser was used to cut polyethylene (PE) with high-density (HD) and low-density (LD) samples, and coloured and transparent polypropylene (PP). Spot shape appeared to affect beam/material interaction performance [4]. A $2700 \mathrm{~W}$ laser used with a rotating drum carrying samples with a thickness from 0.1 down to $0.001 \mathrm{~mm}$ at constant linear velocities of $20 \mathrm{~m} / \mathrm{s}$ showed that weld strength increased for larger beam spot diameters, and elliptical beam spots increased weld efficiency. Coelho et al. [5] have also demonstrated that powerful laser radiation causes changes in the absorbance spectra of epoxy resin, polyethylene, and polysulphone. Thin polymer films were located between IR AgBrCl optical fibres and exposed to the radiation of a $\mathrm{CO}_{2}$ laser. Edward et al. [6] report that plastic colour has a significant effect 


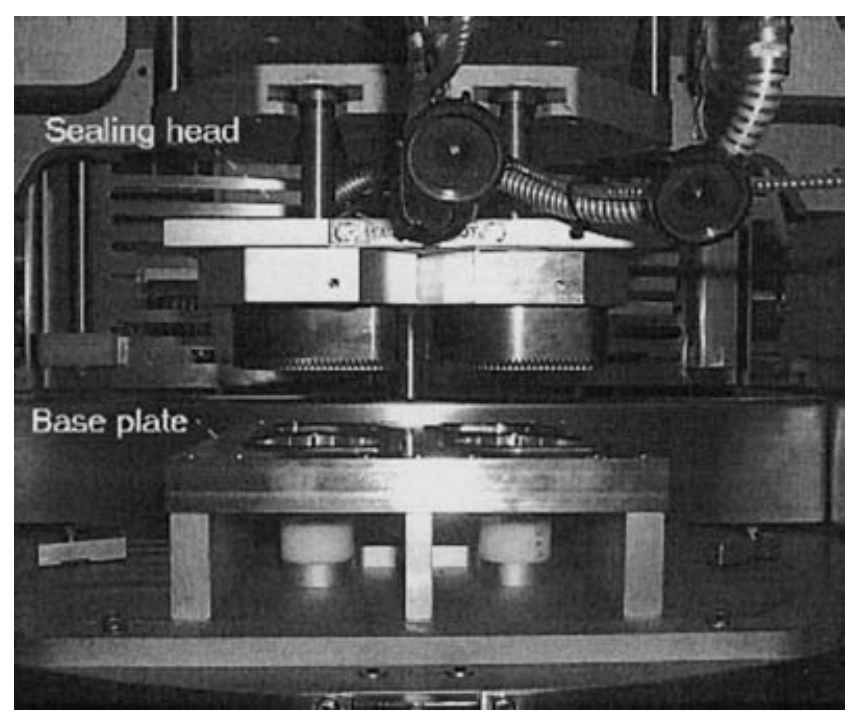

Fig. 1 Conventional package sealing machinery

on absorbance of $\mathrm{Nd}$ : YAG laser radiation, ranging from low attenuation (yellow) through to zero transmission (bottle green). Unfortunately, little is known about the exact colour of plastic samples, but it is clear that material colour has a very low effect on $\mathrm{CO}_{2}$ laser absorbance. Ultrasonically pulsed lasers have been effective in the cutting of metals [7], where cutting without the formation of flashes is possible. Such a method may be applicable to the cutting of polymers, where experimental work carried out by the project team during laser commissioning suggests that thicker polymer films may be cut with a laser gated to acoustic frequencies, with a lower possibility of ignition of polymer vapour for a given laser energy. It is clear that, whichever packaging is used, interaction effects with the conceived packaged product must be considered.

\section{MATERIALS}

A film and pot combination was exposed to a range of laser powers and scan speeds to determine effective weld parameters. A multilayer polypropylene-based film containing a barrier layer, which blocks the passage of oxygen, was used. Barrier films in conjunction with trays with a barrier layer allow a much longer shelf life than monolayer film ( $\approx$ months), a typical application being the storage of ambient ready meals. The structure of the polyethylene vinyl alcohol $(\mathrm{EVOH})$ barrier film was polyester $(12 \mu \mathrm{m}) /$ [nylon/EVOH/nylon] ( $25 \mu \mathrm{m}$ total), and polypropylene (seal layer, $75 \mu \mathrm{m}$ ). Tie layers were incorporated, with a thickness of 1-2 $\mu \mathrm{m}$ each. Polypropylene-faced pots with a similar structure are used for sealing.

\section{LASER SEALING APPARATUS}

The apparatus used consists of a $50 \mathrm{~W}$ Synrad $\mathrm{CO}_{2}$ laser, with power regulated by pulse width modulation (PWM), in conjunction with a galvanometerbased General Scanning Inc. $X-Y$ laser scanner.

\subsection{Laser scanning rig}

The pilot industrial prototype makes use of a modified Packaging Automation PA182 sealing machine, with full film-handling capability, which docks with a scanning laser system. Careful attention must be paid to film handling, since good film contact is necessary for effective sealing. The laser sealing machine can be seen in Fig. 2, and its operation may be described as follows. Film is supplied from the outfeed reel (1) via an electromagnetic brake/clutch arrangement to control film feed. Film take-up is effected by a continuously running motor driving a slipping viscous clutch (2), which achieves fairly constant film tension. The film table (3) is an arrangement of flat plate and guide bars and is used to bring the film into contact with the tray (4). The laser is positioned to the rear of the machine (also viewable to the rear of the photograph) and delivers laser energy via flight tubes and a beam dump to galvanometer-mounted scanning mirrors (6).

\subsection{Laser parameters}

The authors have previously published guidelines [2] for machine parameters for laser sealing at lower scan speeds (of the order of $200 \mathrm{~mm} / \mathrm{s}$ ), and, while it is possible to produce seals with an intact barrier layer, the process is too slow for industrial applications. This paper describes experimental work undertaken further to improve seal quality using a greatly increased laser sealing speed in order to match typical production cycle times. This requires that new laser parameters be established for each tray/film combination. In all the cases described here, laser power was $50 \mathrm{~W}$ (only limited by the laser currently used for experimentation), with a Gaussian $\mathrm{TEM}_{00}$ beam producing a spot size of $1.2 \mathrm{~mm}$. The scan speed was $4.7 \mathrm{~m} / \mathrm{s}$.

\section{EXPERIMENTS}

'Benchmarking trials' based on peel strength testing were carried out to associate numerical values with what were perceived to be 'good' and 'bad' seals. 


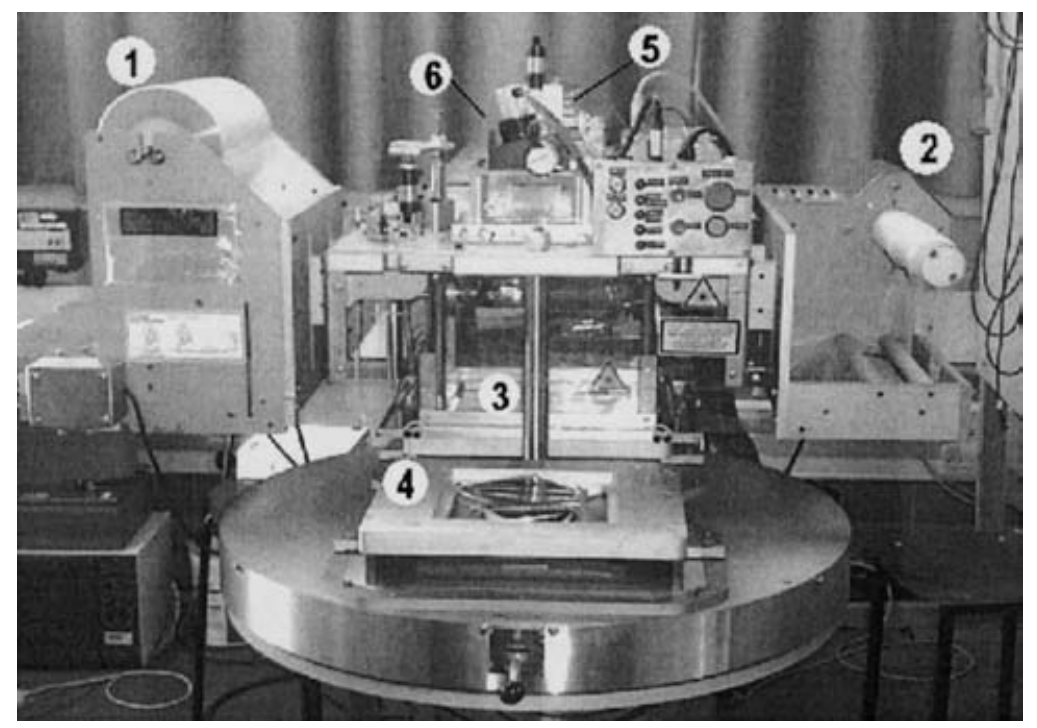

Fig. 2 Laser sealing system

A direct comparison could then be made between samples produced using the laser system and samples produced by conventional heat sealing. Microscopic examination of seal cross-sections was then carried out, followed by further experimentation to establish a modified and improved sealing method.

\subsection{Benchmarking trials: method}

Samples of seals deemed by qualitative assessment to be good or bad were produced by the project industrial partners, without intervention from the research team. The purpose of this exercise was to produce samples categorized purely through the experience and process knowledge of industrial partners. Samples were then subjected to peel tests using a Hounsfield tensometer. In addition to conventional (heat) seals, a large number of laser-sealed pots for multilayer film were prepared, to compare with conventional seal performance.

\subsection{Description of peel tests}

The tray and film were gripped in small jaws and peeled apart at a speed not exceeding $80 \mathrm{~mm} / \mathrm{min}$. Readings were taken for force versus extension. Referring to Fig. 3, results were post-processed as follows.

1. Number of samples. The total number of pots successfully peeled for each batch. This number varies because some films may rip instead of peel, in which case that particular peel test is abandoned, reducing the number of curves plotted.

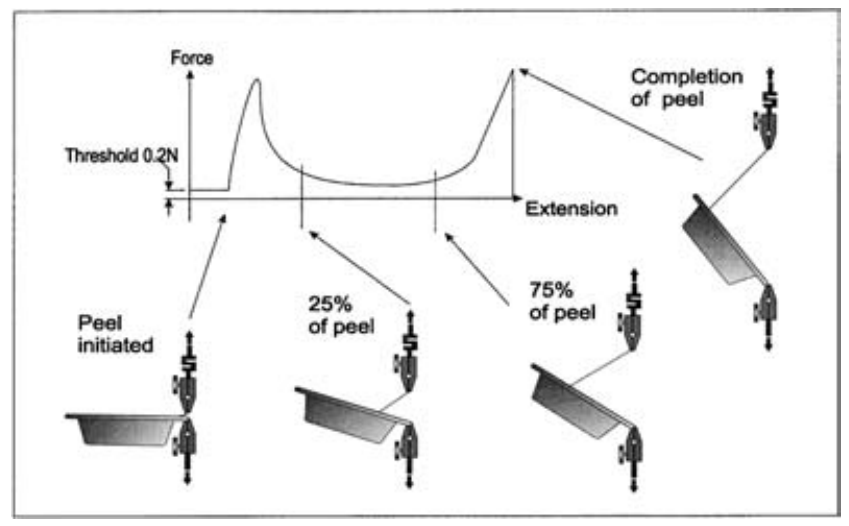

Fig. 3 Peel test overview

2. Maximum force $(\mathrm{N})$. The maximum force encountered during a batch of peel tests.

3. Mean force during the 50 per cent central portion. This is the mean force for all tests between 25 per cent of peel (gauged by extension from when film tension reaches $0.2 \mathrm{~N}$ ) to 75 per cent of peel. The maximum extension for percentage calculation is taken as the point where the peel force drops back to zero (i.e. completion of peel where pot and film are separated). Proportions are automatically calculated with custom software written in Matlab.

4. Mean work done during the 50 per cent central portion. This is force $\times$ distance (area under the curve) for the same area of the plot as step 3 above.

5. Standard deviation (SD) of work done during the 50 per cent central portion. This provides an index of repeatability for each batch of samples. 


\section{RESULTS}

Early peel tests for multilayer film are shown in Fig. 4. Good seals and bad seals were synthesized by an industrial partner, with bad seals produced by altering process variables such as temperature, sealing pressure, or dwell time away from optimum values. Two characteristics of the curves produced are noticeable, firstly that repeatability appears to be good, and secondly that grouping for good and bad samples appears very distinct.

Having established the peel test method, a small batch of tests was carried out with laser sealed pots to establish repeatability. The procedure for performing a laser seal is shown in Fig. 5. In this particular case, a double seal is used to achieve appropriate seal strength, which requires no more space on the pot rim than would a conventional seal.

The repeatability of the laser seals appears to be good. Also noticeable is a classic 'bathtub' shape of the curves owing to the seal being peeled over a greater area during entry and exit of peel. As a result, peel forces are high at the start. While the conventional seals were kept circular for simplicity, a number of modifications to seal geometry have been carried out by some of the industrial partners in the

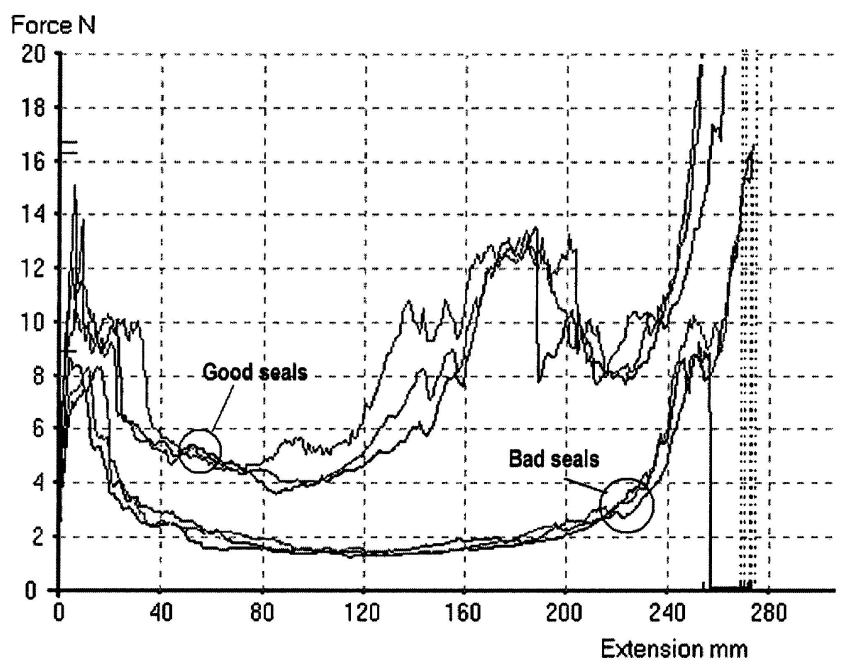

Fig. 4 Peel tests for conventionally sealed pots

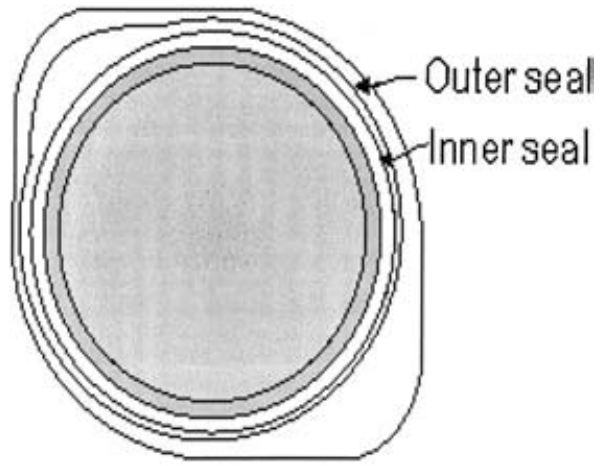

Fig. 5 Dual concentric seals

past to effect a more gradual peel start. As a result, typical sealed pots from the production line usually have much lower entry and exit peel figures while maintaining overall peel strength. This is also the case with the laser seal, which is why the outer seal deliberately follows the edge of the pot rim, as can be seen towards the top of Fig. 5. The numbering of laser passes to produce a dual concentric seal is from the outside inwards, such that, for example, a seal of '50 and 40' passes denotes 50 passes for the outside seal and 40 passes for the inside seal. A triple concentric seal may be seen in Fig. 6 and follows the same numbering convention in that seal passes start with the outside edge.

Results of initial trials are shown in Table 1. It can be seen that the target seal strength as defined by the industrial partners lies between ' 61 and 61

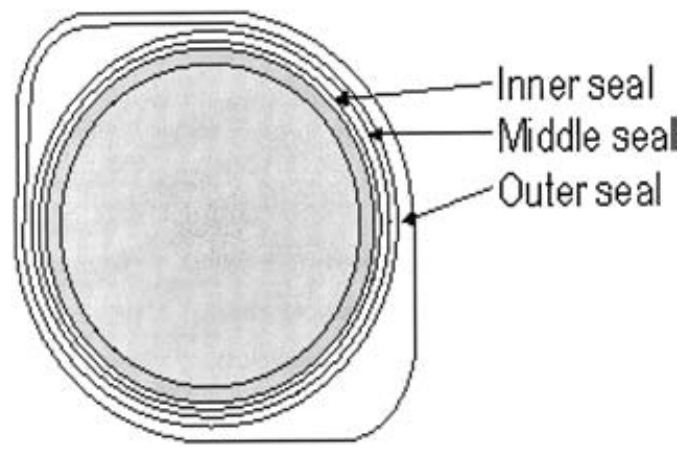

Fig. 6 Triple concentric seals

Table 1 Results from initial laser sealing trials

\begin{tabular}{|c|c|c|c|c|c|}
\hline Test & $\begin{array}{l}\text { Number of } \\
\text { samples }\end{array}$ & $\begin{array}{l}\text { Maximum } \\
\text { force }(\mathrm{N})\end{array}$ & $\begin{array}{l}\text { Mean force } \\
\text { (central 50\%) (N) }\end{array}$ & $\begin{array}{l}\text { Mean work done } \\
\text { (central 50\%) }(\mathrm{J})\end{array}$ & $\begin{array}{l}\text { SD of work done } \\
\text { (central } 50 \% \text { ) }\end{array}$ \\
\hline Conventional (poor seals) & 5 & 17.06 & 2.3106 & 0.3083 & 0.0550 \\
\hline Conventional (good seals) & 5 & 59.55 & 9.7157 & 1.2956 & 0.2975 \\
\hline Laser 80 and 70 concentric & 6 & 68.40 & 14.8788 & 1.9522 & 0.3989 \\
\hline Laser 70 and 60 concentric & 6 & 58.65 & 12.3560 & 1.6451 & 0.2637 \\
\hline Laser 60 and 50 concentric & 5 & 61.13 & 5.6651 & 0.7548 & 0.2143 \\
\hline Laser 65 and 55 concentric & 4 & 61.80 & 6.7321 & 0.8902 & 0.2146 \\
\hline Laser 62 and 61 concentric & 7 & 64.13 & 8.5184 & 1.1426 & 0.2171 \\
\hline
\end{tabular}


concentric' and ' 70 and 60 concentric'. This shows that the laser sealing process may produce a seal of adequate strength. Furthermore, strength (and consequently peelability) may be altered by changing the number of concentric seal passes. Repeatability between laser seals and conventional heat seals compares well, referring to the standard deviation of ' 62 and 61 concentric' and ' 70 and 60 concentric', and the process appears to be slightly more consistent than the conventionally produced good seals. Microscopic examination of seal cross-sections was then carried out to establish the effect of both conventional and laser heat sealing on the film barrier layer.

\subsection{Adoption of a triple concentric seal}

The target seal specification has properties similar to those produced by the conventional heat sealing process as shown in Fig. 7. Some thinning of the barrier layer is present (the darker section just above the joint interface), since it has been squeezed by the sealing process, but oxygen penetration is still within required limits. Microscopic analysis suggested that, while seal strength was adequate, based on the peel trials described in the previous section, material degradation for an ' 80 and 80 pass' duel concentric seal was excessive in that some damage to the $\mathrm{EVOH}$ barrier layer had occurred, which can be clearly seen in Fig. 8. Degradation and distortion of the film has taken place (1), and the substrate itself has distorted (2). The film has also delaminated in places (3). However, a seal with a low number of passes ('50 and 50') had very little visible change in material properties, and no distinguishable remelt of any part of the multilayer film (Fig. 9). In order to combine the advantage of not disrupting the barrier layer with a seal strength equal to that suggested by the 'good' seals supplied by the industrial partner, tests were carried out on multilayer pots and film with a seal

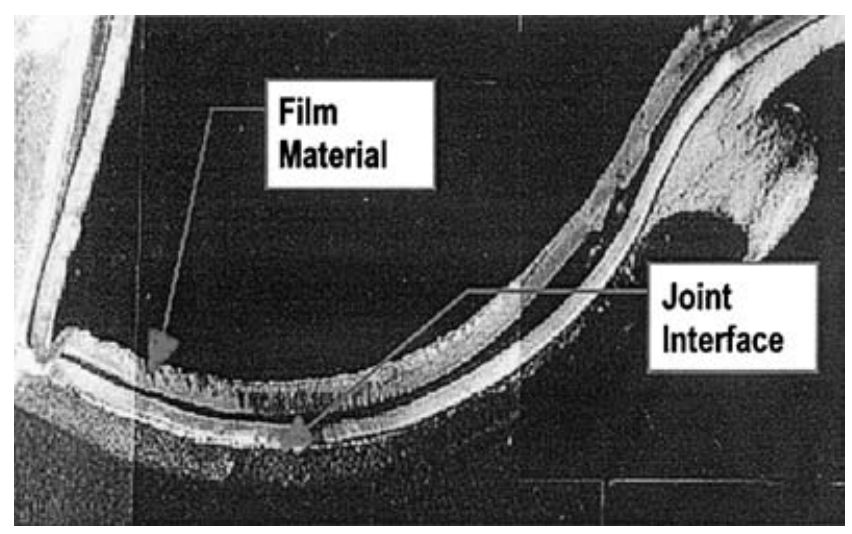

Fig. 7 Conventional seal cross-section showing barrier layer thinning

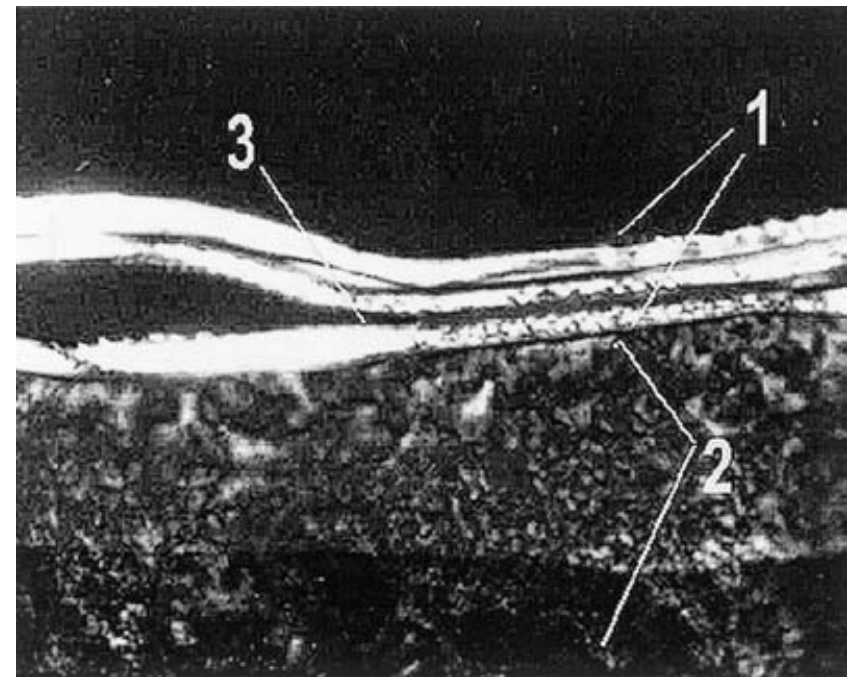

Fig. 8 Laser seal showing damage to the barrier layer

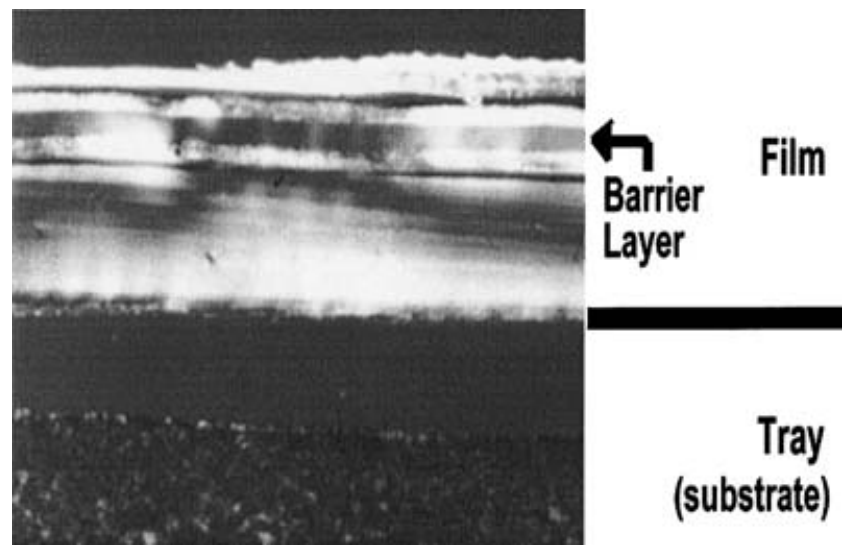

Fig. 9 Laser seal with reduced passes, no visible barrier layer damage

composed of three concentric rings, as shown in Fig. 6, in order to produce a seal strength equivalent to a dual concentric seal, with less barrier layer damage.

A small sample of three results of peel tests for triple concentric sealed pots is shown in Fig. 10. A comparison of peel test results can be seen in Table 2 . Comparing the triple concentric laser seal (50 and 40 and 40 concentric) with a conventional good seal, it can be seen that a seal strength greater than that achieved by the conventional process is possible. The laser sealing process is also slightly more repeatable than the conventional process, with less variation in peel force between samples.

\section{DISCUSSION}

The double concentric laser seal may be used to control accurately the laser seal strength, simply by 
Table 2 Comparison between peel test results for conventional, double, and triple concentric laser seals

\begin{tabular}{llllll}
\hline Test & $\begin{array}{l}\text { Number of } \\
\text { samples }\end{array}$ & $\begin{array}{l}\text { Maximum } \\
\text { force (N) }\end{array}$ & $\begin{array}{l}\text { Mean force } \\
\text { (central 50\%) (N) }\end{array}$ & $\begin{array}{l}\text { Mean work done } \\
(\text { central 50\%) }(\mathrm{J})\end{array}$ & $\begin{array}{l}\text { SD of work done } \\
(\text { central 50\%) }\end{array}$ \\
\hline Conventional (poor seals) & 5 & 17.06 & 2.3106 & 0.3083 & 0.0550 \\
Conventional (good seals) & 5 & 59.55 & 9.7157 & 1.2956 & 0.2975 \\
Laser 80 and 70 concentric & 6 & 68.40 & 14.8788 & 1.9522 & 0.3989 \\
Laser 70 and 60 concentric & 6 & 58.65 & 12.3560 & 1.6451 & 0.2637 \\
Laser 50 and 40 and 40 concentric & 4 & 67.13 & 13.1404 & 1.4837 & 0.1470 \\
\hline
\end{tabular}

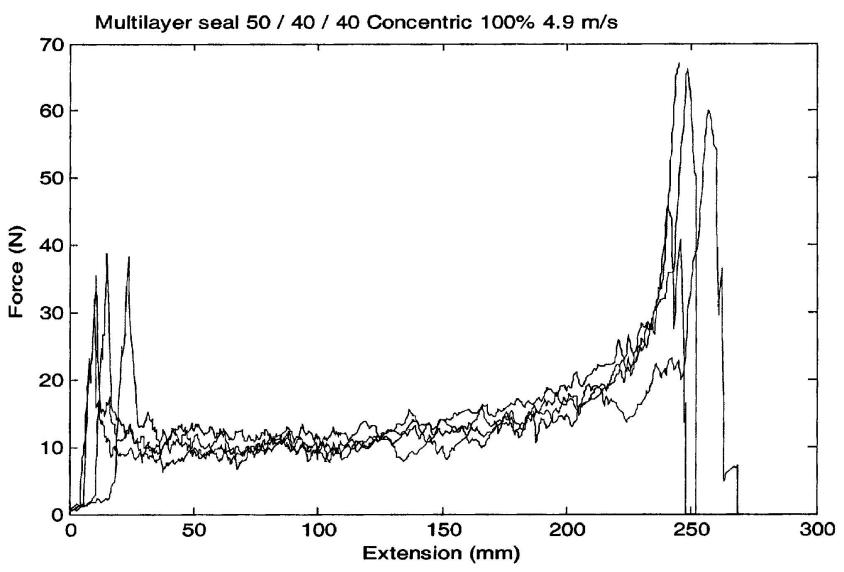

Fig. 10 Peel tests for a triple concentric laser seal

changing the number of passes of the laser. Some damage to the barrier layer is visible, however, when using enough passes of the laser seal to achieve a seal strength of the same magnitude as the conventional process. Microscopic cross-sectioning shows that the adoption of a triple concentric laser seal means that fewer passes of the laser can be used to achieve the same (or greater) seal strength, while greatly reducing any laser damage to the EVOH barrier layer. In order further to evaluate seal integrity, oxygen transmission tests are currently underway at the time of writing to examine the barrier properties of the $\mathrm{EVOH}$ layer after both laser and conventional sealing. Early results suggest that the laser seal is slightly better than the conventional seal for maintaining barrier layer integrity, but, since the oxygen transmission test can be unreliable and a small number of tests not representative, the authors have decided to produce a statistically representative set of oxygen transmission results in a future paper.

\subsection{Design considerations for laser sealing systems}

As a result of initial research, the following are known to be influencing factors in the refinement/expansion of material choices for laser sealing systems: (a) interaction of laser beam radiation with the barrier layers and seal layer (transmissive);

(b) interaction of the laser beam heat effect with the barrier layers and seal layer (conductive);

(c) degradation products of polymers (cutting involves vaporization of polymer film) must be known, and actions taken to protect machine operators, particularly when cutting;

(d) filler material - effects on absorption of laser energy may require fine tuning of laser power.

The following are useful to note when designing thin film laser sealing systems, and are gleaned from the experimental work described above:

(a) careful film handling (spreading of the web) is critical to maintaining a good seal, while film tensioning drastically improves process reliability;

(b) focusing of the laser is not always necessary for sealing, raw spot sizes of around $2-4 \mathrm{~mm}$ often producing good results;

(c) pulsing of the laser assists cutting;

(d) performing a 'multipass' welding operation has proved effective, whereby up to 50 passes at high scan speed $(\sim \mathrm{m} / \mathrm{s})$ may seal with minimal disruption and at higher cycle rates than using a lower scan speed and lower laser power.

\section{CONCLUSIONS}

A process has been demonstrated that, using a beamsteered laser in place of conventional thermal tooling, completely removes the need for top tooling and greatly reduces the necessary mass of any bottom tooling, thereby lowering considerably the necessary machine stiffness, weight, and cost.

The choice of laser power and scan speed is important in producing a good seal, but the effect of material thermal time constants must not be ignored. While the upper limit of processing speed for laser sealing of polymer film has yet to be defined, it is becoming clear that material choice is important for higher speeds, as well as careful choice of sealing 
strategy, if the components of the film are to remain undamaged. There is no reason at this point not to believe that, with regard to cycle times, a system with a more powerful laser could eventually exceed the conventional process in cycle speed. Reduction in cycle times is assisted by the adoption of sealing strategies such as multipass operation, greatly improving seal repeatability.

\section{ACKNOWLEDGEMENTS}

The authors would like to thank the project industrial partners Packaging Automation Limited, GSI Lumonics Limited, The Recipe Dish Company Limited, FFP Packaging Solutions Limited, and RPC Containers Limited. The project is funded under the DEFRA/LINK Programme Code AFM114, 'Intelligent Package Sealing and Inspection System for Semirigid Food Containers' (http://www.defra.gov.uk/).

\section{REFERENCES}

1 Brown, N., Kerr, D., Jackson, M. R., and Parkin, R. M. Laser welding of thin polymer films to container substrates for aseptic packaging. Optics and Laser Technol., 2000, 32(2), 139-146.
2 Brown, N., Shi, F., Kerr, D., Jackson, M. R., and Parkin, R. $\mathrm{CO}_{2}$ laser processing of packaging films including multi-layer laminates containing silicon oxide and ethylene vinyl alcohol barriers. In Proceedings of ICOM03 International Conference on Mechatronics, Loughborough, Leicestershire, 18 June 2003, pp. 383-388.

3 Coelho, J. P., Abreu, M. A., and Pires, M. C. Highspeed laser welding of plastic films. Optics and Lasers in Engng, 2000, 34(4-6), 385-395.

4 Coelho, J. P., Pedro, M., and Pires, M. C. Laser cutting of superposed plastic films. In International Conference on Lasers 98, 1998 (STS Press, Tuczon, Arizona).

5 Coelho, J. P., Abreu, M. A., and Pires, M. C. Influence of laser spot shape on welding of thin thermoplastics. In Proceedings of Laser Materials Processing Conference ICALEO 2000, 2000 (Laser Institute of America).

6 Pogreb, E. B. R., Sheshnev, A., Shulzinger, E., Bormashenko, Y., and Abraham, K. IR laser radiation induced changes in the IR absorption spectra of thermoplastic and thermosetting polymers. J. Optics A: Pure and Appl. Optics, 2001, 3, 229-235.

7 Gureev, D. M. Prospects for laser-ultrasonic treatment for surface modification, welding, and pattern cutting. J. Russ. Laser Res., 1999, 20(1), 27-66.

8 Coelho, J. P., Sampaio, M., and Pires, M. C. Thin plastic films optical parameters for $\mathrm{CO}_{2}$ and $\mathrm{Nd}$ : YAG lasers radiation. In International Conference on Lasers 98, 1998 (STS Press, Tuczon, Arizona). 